\title{
artigo
}

Macêdo, A.G.A.O.; Freitas, C.A.S.L.; Monteiro da Silva, M.A.; Melo, E.S; Mazza, V.A.; Oliveira, C.M.; Rosa, B.S.C.;

Percepções e sentimentos de familias de crianças com transtorno do espectro autista

DOI: https://doi.org/10.36489/saudecoletiva.2021v11i68p7555-7564

\section{Percepções e sentimentos de famílias de crianças com transtorno do espectro autista}

Feelings of families of children with autistic spectrum disorder

Sentimientos de familias de niños con trastorno del espectro autistico

\begin{abstract}
RESUMO
Objetivo: Identificar as percepções e sentimentos das famílias de crianças com Transtorno do Espectro Autista. Métodos: Pesquisa descritiva com abordagem qualitativa, teve como participantes as famílias de crianças com Transtorno do Espectro Autista (TEA) acompanhadas em um Centro de Reabilitação de um município do Ceará, no período de julho a setembro de 2018. Para coleta de informações foi aplicado um roteiro de entrevista semi-estruturada. As informações foram analisadas a partir da análise de conteúdo. Resultados: Emergiram as seguintes categorias: (1) Percepções dos familiares sobre a criança com TEA na família e (2) Sentimentos dos familiares referentes a criança com TEA. Conclusão: 0 diagnóstico de TEA revela repercussões importantes no âmbito familiar. As condições emocionais dos familiares cuidadores das crianças com TEA interferem na efetividade dos processos de intervenção precoce.
\end{abstract}

DESCRITORES: Família; Relações Familiares; Características da Família; Criança; Autismo infantil.

\section{ABSTRACT}

Objective: To identify the perceptions and feelings of families of children with Autistic Spectrum Disorder. Methods: Descriptive research with a qualitative approach, had as participants the families of children with Autistic Spectrum Disorder (ASD) followed at a Rehabilitation Center in a city in Ceará, from July to September 2018. For information collection, it was applied a semi-structured interview script. The information was analyzed based on content analysis. Results: The following categories emerged: (1) Perceptions of family members about the child with ASD in the family and (2) Feelings of family members regarding the child with ASD. Conclusion: The diagnosis of ASD reveals important repercussions in the family environment. The emotional conditions of family caregivers of children with ASD interfere in the effectiveness of early intervention processes.

DESCRIPTORS: Family; Family Relations; Family Characteristics; Child; Childhood Autismo.

\section{RESUMEN}

Objetivo: Identificar las percepciones y sentimientos de las familias de niños con Trastorno del Espectro Autista. Métodos: Investigación descriptiva con abordaje cualitativo, tuvo como participantes a las familias de niños con Trastorno del Espectro Autista (TEA) seguidos en un Centro de Rehabilitación de una ciudad de Ceará, de julio a septiembre de 2018. Para la recolección de información se aplicó un semi- guión de entrevista estructurado. La información se analizó mediante análisis de contenido. Resultados: Surgieron las siguientes categorías: (1) Percepciones de los miembros de la familia sobre el niño con TEA en la familia y (2) Sentimientos de los miembros de la familia con respecto al niño con TEA. Conclusión: El diagnóstico de TEA revela importantes repercusiones en el ámbito familiar. Las condiciones emocionales de los cuidadores familiares de niños con TEA interfieren en la efectividad de los procesos de intervención temprana.

DESCRIPTORES: Familia; Relaciones Familiares; Composición Familiar; Niño; Autismo Infantil.

RECEBIDO EM: 15/03/2021 APROVADO EM: 04/06/2021

\section{Antônia Gabriela Aragão de Oliveira Macêdo}

Enfermeira. Discente do Mestrado Acadêmico em Saúde da Família da Universidade Federal do Ceará (UFC).

ORCID: 0000-0002-7366-2043

\section{Cibelly Aliny Siqueira Lima Freitas}

Doutora em Enfermagem. Docente do Curso de Enfermagem da Universidade Estadual Vale do Acaraú (UVA).

ORCID: 0000-0002-0585-5345 
Maria Adelane Monteiro da Silva

Doutora em Enfermagem. Docente do Curso de Enfermagem da Universidade Estadual Vale do Acaraú (UVA).

ORCID: 0000-0001-7579-2645

Etelvina Sampaio Melo

Mestre em Saúde da Família. Enfermeira Assistente do Hospital Regional Norte (HRN).

ORCID: 0000=0001-5099-6553

Verônica de Azevedo Mazza

Doutora em Enfermagem. Docente do Curso de Mestrado em Enfermagem da Universidade Federal do Paraná (UFPR).

ORCID: 0000-0002-1264-7149

\section{Camila Martins de Oliveira}

Mestre em Saúde da Família pela Universidade Federal do Ceará (UFC).

ORCID: 0000-0003-1592-0013.

\section{Benedita Shirley Carlos Rosa}

Discente do Curso de Enfermagem da Universidade Estadual Vale do Acaraú (UVA).

ORCID: 0000-0002-9125-3614

\section{INTRODUÇÃO}

$\mathbf{N}$ o Brasil, de acordo com a Lei ${ }^{\circ}$ 12.764 o Transtorno do Espectro Autista (TEA) é considerado uma deficiência e integra a quinta versão do Diagnostic and Statistical Manual of Mental (DSM), caracterizando-se pelo prejuízo funcional nas áreas da comunicação, da interação social e do comportamento ${ }^{1,2}$. No que tange à epidemiologia, segundo a Organização das Nações Unidas (ONU), cerca de 70 milhóes de pessoas no mundo são acometidas pelo TEA, sendo que, em crianças, é mais comum que o câncer, a AIDS e o Diabetes mellitus ${ }^{3}$.

A criança com TEA demanda maiores cuidados e atenção dos pais ou cuidadores, portanto, acredita-se que isso produza impactos na família, já que são muitas as dificuldades a enfrentar para socializar os filhos. Além disso, as expectativas criadas por toda uma vida que os pais tendem a fazer acerca da vida dos filhos geram um conjunto de frustrações no momento do diagnóstico. Soma-se a isso, conflitos decorrentes do estresse que os pais vivenciam, irritabilidade da rotina, entre outros ${ }^{4}$.

Ao se deparar com o diagnóstico de TEA vários sentimentos se manifestam sobre os pais e família. Dentre eles a perda do filho idealizado, sentimentos de tristeza, insegurança quanto a nova realidade, mudanças na rotina familiar e impotência quanto ao provimento de cuidados, este centralizado à criança 5 .

Entender a série de implicações que surgem na vida dos pais de crianças com transtorno do espectro autista, a dinâmica do TEA, o modo como à intervenção precoce pode impactar favoravelmente no desenvolvimento são pontos essenciais aos pais que devem ser ofertados no diagnóstico ou suspeita do TEA 6 . Nessa perspectiva, o enfermeiro assume papel importante no que concerne ao suporte às crianças com TEA e seus familiares, ao reconhecer os pontos mais relevantes na relação pais-crianças atípicas, pode-se propor medidas que informem e comuniquem não somente familiares, mas população em geral que ainda pouco compreende o que é o TEA 7 .

A discussão sobre o TEA nos diferentes contextos em que as crianças estão inseridas, representa uma necessidade de conhecimentos sobre o que é o espectro autista e as desmitificações de estereótipos, propondo novos olhares e interpretações, mediante as possibilidades de cuidados e integração social da criança com TEA e da família ${ }^{8}$.

Deste modo, o TEA vem ocupando a agenda das políticas públicas brasileiras, no entanto, ainda é preciso avançar na construção de redes locais potentes, que sustentem a clínica ampliada com crianças, organizando o cuidado de modo a não sobrecarregar os familiares, nem negligenciar suas necessidades, priorizando o diálogo a fim de se compreender as suas percepçôes e sentimentos?.

A partir da experiência vivenciada no cuidado de uma criança com TEA, surgiram inquietações referentes a pouca aceitação dos comportamentos autísticos pela sociedade e por outros familiares, assim como uma rotina intensa necessária ao cuidado das crianças. Desse modo, este estudo teve como objetivo identificar as percepções e sentimentos das famílias de crianças com Transtorno do Espectro Autista.

\section{MÉTODOS}

Estudo descritivo, com abordagem qualitativa. $\mathrm{O}$ artigo originou-se de um estudo multicêntrico intitulado por "Vivências de famílias constituídas com crianças com deficiência: Organização, Práticas e Necessidades" com financiamento do Conselho Nacional de Desenvolvimento Científico e Tecnológico (CNPq), foi aprovado no Comitê de Ética de Pesquisa do Programa de Pós-Graduação em Enfermagem (UFPR) sobre o CAAE: 73197617.0.1001.0102, com o parecer $\mathrm{n}^{\circ}$ 2.806.799. Encontra-se vinculado ao Grupo de Estudos em Vulnerabilidade em Saúde (GEVS) da Universidade Estadual Vale do Acaraú (UVA).

O cenário da pesquisa foi um Centro de Reabilitação que oferece atendimento a crianças com necessidades especiais, lo- 
calizado no município de Sobral, Ceará, Brasil. Os participantes foram os 24 familiares de crianças com TEA atendidos pelo serviço supracitado. Os critérios de inclusão consistiram nos familiares de crianças com diagnóstico de TEA na faixa etária de 3 a 10 anos.

A coleta de informações foi realizada no período de julho a setembro de 2018 . $\mathrm{O}$ instrumento aplicado foi um roteiro de entrevista semi-estruturada consistindo em questionamentos sobre o cotidiano de vida dos familiares de crianças com TEA.

As informações foram analisadas a partir do referencial de Bardin que utiliza a associação de métodos qualitativos por meio da análise categorial temática ${ }^{10}$. Emergiram as categorias: (1) Percepções

Tabela 1 - Distribuição dos dados dos participantes da pesquisa, familiares de crianças com Transtorno do Espectro Autista, Sobral, Ceará, Brasil, 2018.

\section{VARIÁVEIS}

Parentesco

\begin{tabular}{|c|c|c|}
\hline & Pais & 01 \\
\hline & Avó & 01 \\
\hline & Irmão(a) & 01 \\
\hline \multirow[t]{2}{*}{ Sexo } & Masculino & 01 \\
\hline & Feminino & 13 \\
\hline \multirow[t]{3}{*}{ Idade } & 20 a 30 & 03 \\
\hline & 31 a 40 & 08 \\
\hline & 41 a 50 & 03 \\
\hline \multirow[t]{6}{*}{ Escolaridade } & Ens. Fundamental Incompleto & 01 \\
\hline & Ens. Médio Completo & 02 \\
\hline & Ens. Médio Incompleto & 03 \\
\hline & Ens. Superior Completo & 05 \\
\hline & Ens. Superior Incompleto & 01 \\
\hline & Ens. Técnico Completo & 02 \\
\hline \multirow[t]{5}{*}{ Situação Civil } & Solteiro & 04 \\
\hline & Casado & 06 \\
\hline & União Estável & 02 \\
\hline & Divorciado & 01 \\
\hline & Viúvo & 01 \\
\hline \multirow[t]{3}{*}{ Renda Mensal } & 1 salário mínimo & 03 \\
\hline & 1 a 2 salários mínimos & 09 \\
\hline & Acima de 3 salários mínimos & 02 \\
\hline
\end{tabular}

Mães dos familiares sobre a criança com TEA na família e (2) Sentimentos dos familiares referentes a criança com TEA.

O estudo obedeceu aos preceitos éticos da Resolução n ${ }^{\circ}$ 510/16 do Conselho Nacional de Saúde, que dispõe sobre as normas aplicáveis a pesquisa em Ciências Humanas e Sociais cujos procedimentos metodológicos envolvam a utilização de dados diretamente obtidos com os participantes ou de informações identificáveis ou que possam acarretar riscos maiores do que os existentes na vida cotidiana ${ }^{11}$. Os participantes assinaram o Termo de Consentimento Livre e Esclarecido, que informava sobre os riscos e benefícios, bem como sobre a garantia de anonimato.

.


Identificou-se em outros discursos que alguns entrevistados apresentam dificuldades no processo de cuidado mesmo adquirindo o conhecimento sobre TEA:

\section{É difícil, né... Conviver, porque a maioria da gente não sabe como é que luta com a criança que tem, assim como é que vai ser a convivência da gente com ela? Que é difícil da gente entender as coisas dela [...] (E2) \\ $E$ difícil [...] um pouco difícil, mas tá dando, tá dando pra (pausa e respiração profunda) aceitei nor- mal tem outros casos na família com crianças especiais. (E3)}

Nota-se nas falas o desafio para as famílias no processo de aprendizagem e o comportamento da criança:

... eu não sabia o que ele tinha e eu queria educar ele como os outros, levar pra missa e queria que ele ficasse sentando que nem eu fazia com meus outros filhos e com ele eu não consigo. Então como eu queria fazer da maneira que não é a maneira dele, queria fazer da minha maneira eu nunca conseguia e depois que eu descobri tudo ficou mais fácil por que eu consigo fazer as coisas com ele no tempo dele. (E2)

[...] nas crises é difícil, mas às vezes eu nem penso que ela é autista. Só no aprendizado, só lembro que ela é autista na hora de estudar, porque eu penso que ela não vai aprender. (E12)

\section{Sentimentos dos familiares referen- tes a criança com TEA}

Conhecer os sentimentos e as emoções dos familiares possibilita o desempenho no processo de cuidado da criança com TEA, neste estudo encontrou-se diversos sentimentos que configuram pontos que favorecem ao desempenho da criança. Entre os mais descritos pelos participantes, identificou-se o sentimento de gratidão e alegria por conviver com uma criança com TEA:

Mas assim normal eu não vejo nenhuma diferença assim, nenhuma anormalidade e assim da mais alegria que os outros a inteligência é incomparável. (E9)

Ele fala, ele anda... é difícil tudo para ele é mais difícil, mas eu sou é agradecida por ser autismo. (E1)

Outra questão mencionada nas falas é anseio dos participantes que têm filhos neurotípicos e a nova experiência da maternidade e paternidade com os filhos atípicos, observa-se que os familiares realizam comparativos:

[...] que mesmo eu achando ele diferente eu não sabia o que ele tinha e eu queria educar ele como os outros filhos, levar pra missa e queria que ele ficasse sentando que nem eu fazia com meus outros filhos e com ele eu não consigo. (E10)

Não sei dizer como foi, por que os meus dois meninos não é... e ai esse último menino ele nasceu autista, sei lá é como mãe de primeira viagem. (E 13)

\section{DISCUSSÃO}

As mudanças ocorridas na estrutura familiar na sociedade contemporânea, realçam a entrada das mulheres no mercado de trabalho, a sua assunção, de um papel mais ativo na vida social e a sua maior contribuição para a subsistência econômica da família. Consequentemente, o aumento do número de famílias em que ambos os pais trabalham, levando a uma maior necessidade de as tarefas familiares serem redistribuídas ${ }^{6}$. Neste contexto, a mãe de uma criança com TEA passa a vivenciar diferentes estressores no processo de ser mãe e cuidadora principal.

Um estudo realizado com familiares de crianças com transtorno do espectro autista no Rio Grande do Sul, corrobora com o supracitado ao mencionar que frente às demandas características do TEA, foram principalmente as figuras femininas que deixaram de trabalhar para se dedicarem integralmente aos cuidados com a criança ${ }^{12}$.

Neste contexto, as famílias se deparam com intensas mudanças em suas atividades diárias em vista das demandas da criança com TEA ${ }^{12}$. No estudo das experiências e demandas cotidianas no contexto de cuidados de filhos diagnosticados com transtorno do espectro autista, identificou-se que as famílias organizam sua rotina em função da criança, tanto a rotina domiciliar, quanto a rotina social ${ }^{13}$.

Em estudo sobre subjetividade e cuidado na hospitalização pediátrica relacionado as vulnerabilidades das crianças com necessidades especiais, observa-se a reflexão para o trabalho com crianças com condições crônicas e complexas de saúde dentre elas as deficiências e TEA, exigindo destreza e sensibilidade dos profissionais para o reconhecimento e interpretação da subjetividade da criança e família ${ }^{14}$.

Outro aspecto a ser mencionado é a limitação financeira, que pode ser um impasse ao tratamento especializado por envolver o acompanhamento com profissionais de diversas áreas, o que pode ser oneroso. Ademais, a renda familiar assim direcionada poderia prejudicar necessidade dos demais membros e as despesas comuns ao lar, o que pode comprometer o lazer e outras atividades da família. Há, portanto, a necessidade de considerar neste contexto, as questões de ordem financeira e a vida de todos os membros do grupo familiar ${ }^{15}$.

Em relação ao nível de escolaridade dos participantes um relevante percentual apresentou grau de escolaridade com mais anos de estudo, o que beneficia a compreensão da condição crônica do TEA e o reconhecimento da importância do seu tratamento. A literatura recomenda que a família deva buscar conhecer o TEA após o diagnóstico como forma a favorecer a aceitação dessa nova condição entre os familiares e facilitar o cuidado. O envolvimento em grupos de apoio, também, é sugerido para auxiliar no enfrentamento dos desafios e compartilhamento de experiências, tornando-se assim, mais capacitada e preparada para o convívio saudável ${ }^{16}$.

Embora, o diagnóstico de TEA possa representar um desafio para os familiares, observa-se, que a compreensão sobre o 


\section{artigo}

TEA e os sentimentos positivos da família pela criança, superam as dificuldades e impasses, mediante afeto e ensinamentos adquiridos nessa relação. Dessa forma, as condiçỗes emocionais dos pais aumentam a efetividade de processos de intervenção precoce ${ }^{17}$. Essas evidências sinalizam a importância de um olhar recíproco entre os efeitos da criança com TEA no sistema familiar e o impacto do contexto familiar sobre a criança com TEA em função do papel das relações familiares que estão envolvidas nos processos sociais e comunicativos associados ao TEA $^{18}$.

\section{CONCLUSÃO}

O diagnóstico de TEA revela repercussões importantes no âmbito familiar, sendo atribuído ao desconhecimento acerca do assunto e sentimentos positivos atribuídos a superação de desafios. Deste modo as condições emocionais dos familiares de crianças com TEA interferem na efetividade dos processos de intervenção precoce. Acredita-se que identificar as percepções e sentimentos das famílias de crianças com TEA possibilita uma assistência mais humanizada e especializada, conforme as particularidades de cada criança e da família.

\section{REFERÊNCIAS}

1. Presidência da República (Brasil). Lei n ${ }^{\circ}$ 12.764, de 27 de dezembro de 2012. Institui a Política Nacional de Proteção dos Direitos da Pessoa com Transtorno do Espectro Autista; e altera o $§ 3^{\circ}$ do art. 98 da Lei $n^{\circ}$ 8.112, de 11 de dezembro de 1990 [internet]. Diário oficial da união. 2012 dez. 27. [acesso em 02 set 2018]. Disponível em: http://www.planalto.gov.br/ccivil_03/_ato2011-2014/2012/ lei/I12764.htm.

2. American Psychiatric Association (APA). Diagnostic and statiscal manual of mental disorderes. 5 th ed. Washington (DC): American Psychiatric Association; 2013. [cited 2018 Sep 02]. Available from: https://www.psychiatry.org/psychiatrists/practice/dsm.

3. Silva ABB, Gaiato MB, Reveles LT. Mundo singular: entenda o autismo. $1^{\text {a }}$ ed. Rio de Janeiro: Fontanar; 2012.

4. Misquiatti ARN, Brito MC, Ferreira FTS, Assumpção JFB. Sobrecarga familiar e crianças com transtornos do espectro do autismo: perspectiva dos cuidadores. Rev CEFAC [Internet]. 2015 [acesso em 02 set 2018]. 17(1):192-200. Disponivel em: https://www. scielo.br/pdf/rcefac/v17n1/1982-0216-rcefac-17-01-00192.pdf.

5. Souza RFA, Souza JCP. Os desafios vivenciados por famílias de crianças diagnosticadas com transtornos de espectro autista. Perspectivas em Diálogo. 2021[acesso em 03 jun 2021]. 8(16):164182. Disponivel em: https://periodicos.ufms.br/index.php/persdia/ article/view/10668.

6. Rodrigues JIB, Fernandes SMGC, Marques GF dos S. Preocupações e necessidades dos pais de crianças hospitalizadas. Saúde Soc [Internet]. 2020 [acesso em 25 out 2020]. 29(2):e190395. Disponível em: https://www.revistas.usp.br/sausoc/article/view/175902.

7. Dartora DD, Mendieta MC, Franchini B. A equipe de enfermagem e as crianças autistas. J. Nurs health [Internet]. 2014 [acesso em 02 set 2018]. 4(1):27-38. Disponivel em: https://periodicos.ufpel.edu. br/ojs2/index.php/enfermagem/article/view/4304.

8. Araújo JC, Morais AC, Silva MT, Amorim RC, Souza SL. Cuidar de crianças autistas: experiências de familiares. REAS [Internet]. 2020 [acesso em 2 jun 2021] 12(2):e2138. Disponivel em: https://acervomais.com.br/index.php/saude/article/view/2138.

9. Lima RC, Couto MCV. Percepções sobre o autismo e experiências de sobrecarga no cuidado cotidiano: estudo com familiares de CAPSi da região metropolitana do Rio de Janeiro. Cadernos Brasileiros de Saúde Mental. 2020 [acesso em 2 jun 2021] 12(31):217-244. Disponivel em: https://periodicos.ufsc.br/index.php/cbsm/article/ view/69760.

10. Bardin L. Análise de conteúdo. São Paulo: Edições 70; 2016.

11. Conselho Nacional de Saúde (BR). Resolução nº 510 de 07 de abril de 2016. Dispõe sobre as

normas aplicáveis a pesquisa em Ciências Humanas e Sociais. Conselho Nacional de Saúde.

Brasilia, 2016. [acesso em 03 jun 2021]. Disponível em:

http://conselho.saude.gov.br/resolucoes/2016/Res0510.pdf.

12. Machado MS, Londero AD, Pereira CRR. Tornar-se familia de uma criança com transtorno do espectro autista. Contextos Clínic. 2018 [acesso em 03 jun 2021] 11(3):335-350. Disponível em: http://pepsic.bvsalud.org/pdf/cclin/v11n3/v11n3a06.pdf.

13. Minatel MM, Matsukura TS. Familias de crianças e adolescentes com autismo: cotidiano e realidade de cuidados em diferentes etapas do desenvolvimento. Revista de Terapia Ocupacional da Universidade de São Paulo. 2014 [acesso em 03 jun 2021] 25(2):126-134. Disponível em: https://www.revistas.usp.br/rto/ article/view/65682.

14. Santos RA, Minayo MCS. Subjetividade e cuidado na hospitalização pediátrica. Saúde Coletiva (Barueri). 2019 [acesso em 03 jun 2021] 50(09):1823-1830. Disponivel em: http://www.revistas.mpmcomunicacao.com.br/index.php/saudecoletiva/article/view/164.

15. Bosa CA. Autismo: intervenções psicoeducacionais. Rev bras psiquiatr [Internet]. 2006 [acesso em 03 mai 2019]. 28(1):47-53. Disponível em: https://www.scielo.br/pdf/rbp/v28s1/a07v28s1. pdf.

16. Onzi FZ, Gomes RF. Transtorno do Espectro Autista: a importância do diagnóstico e reabilitação. Caderno pedagógico [Internet]. 2015 [acesso em mai 2019]. 12(3):188-199. Disponível em: http://www.univates.br/revistas/index.php/cadped/article/ view/979/967.

17. Wachtel K, Carter AS. Reaction to diagnosis and parenting styles among mothers of young children with ASDs. Autism. 2008 [cited 2020 Sep 02] 12(5):575 594. Available from: https://pubmed.ncbi. nlm.nih.gov/18805948/.

18. Andrade AA, Teodoro MLM. Família e autismo: uma revisão da literatura. Contextos Clínicos [Internet]. 2012 [acesso em 03 mai 2019]. 5(2):133-142. Disponivel em: http://revistas.unisinos.br/index.php/contextosclinicos/article/view/ctc.2012.52.07/1212. 